\title{
From flowers to palms: 40 years of policy for online learning
}

\author{
Janice Smith* \\ University College London, UK
}

\begin{abstract}
This year sees the 40th anniversary of the first policy paper regarding the use of computers in higher education in the United Kingdom. The publication of this paper represented the beginning of the field of learning technology research and practice in higher education. In the past 40 years, policy has at various points drawn from different communities and provided the roots for a diverse field of learning technology researchers and practitioners. This paper presents a review of learning technology-related policy over the past 40 years. The purpose of the review is to make sense of the current position in which the field finds itself, and to highlight lessons that can be learned from the implementation of previous policies. Conclusions drawn from the review of 40 years of learning technology policy suggest that there are few challenges that have not been faced before as well as a potential return to individual innovation.
\end{abstract}

\section{Introduction}

I think there is a world market for maybe five computers. (Watson, 1943)

... it is clear that virtual learning is an industry which is striding forward all around us

... (David Blunkett, 2000)

This year sees the 40th anniversary of the first policy paper regarding the use of computers in higher education in the United Kingdom. While this makes learning technology research a relative newcomer in relation to established disciplines such as philosophy, it is perhaps not as young as we sometimes think. One marker of the discipline coming of age is the existence of sufficient literature to enable us to look back and to make sense of how we have arrived at this point, rather than just looking forward. Recent reviews in the pages of $A L T-\mathcal{F}$ (Conole, 2002; Ravenscroft, 2003), the British Fournal of Educational Technology's 30th anniversary issue (Hawkridge, 1999) and Gosling's (2001) survey of educational development activity illustrate

\footnotetext{
*Department of Electronic \& Electrical Engineering, University College London, Torrington Place, London WC1E 6JE, UK. Email: jsmith@ee.ucl.ac.uk
} 
this trend. In this paper, I continue this direction by summarising the policy context for online learning over the past 40 years, which can be characterised into four phases:

- time-share and expert operators;

- distributed resources and early adopters;

- networking technologies and collaboration; and

- politicisation, systematisation and learner-centrism.

Within these phases, six key policy themes are evident: technology development, technology deployment, software development, communications and networking technologies, staff development, and learner-centrism. It is suggested that the policy themes that dominated each of these phases were a function of technological developments. Whatever the aim, as policy was cast, intentions were limited by the available or envisaged tools.

The dangers of a policy review are plain, and probably multiplied, in a fast-moving area like learning technology. Any review is likely to be out of date almost as soon as it is written. This is particularly true in this instance, as we await the finalised Higher Education Funding Council for England (HEFCE) e-learning strategy and await the complex fall-out from the UK e-University (UKeU) venture to provide insights for future policy (House of Commons Education and Skills Committee, 2005). What follows then, is a review of the first 40 years, moving from early, centralised services to the highly political animal of the current era. A more detailed review of early policy is provided by Smith (2004). For reasons of space, policies regarding UK higher education more generally are also not included in this paper. However, Barnett (1994, 2000) and McNay (2000) provide excellent in-depth accounts of the wider context for this review.

\section{The birth of learning technology policy}

In 1965, the Flowers report led to the setting up of the Computer Board for Universities and Research Councils (CBURC). The CBURC was in existence for 25 years, through a rapid phase of technological development. In its final report, the Board recognised that this period signifies a time:

during which ... the use of computers in universities spread from being the preserve of a few specialists to the point where computers are used extensively in all subjects.

(CBURC, 1991, p. 11)

A chronology summarising the shift from specialist service to pervasive computer use is illustrated in Figure 1. This illustrates that a profound shift in technology availability, cost and pervasiveness opened many avenues for development. From 1965 to the present time, it is reasonable to suggest that real progress has been made in five distinct areas:

- Technology development - the development of cheaper, smaller, faster, more powerful computers. 


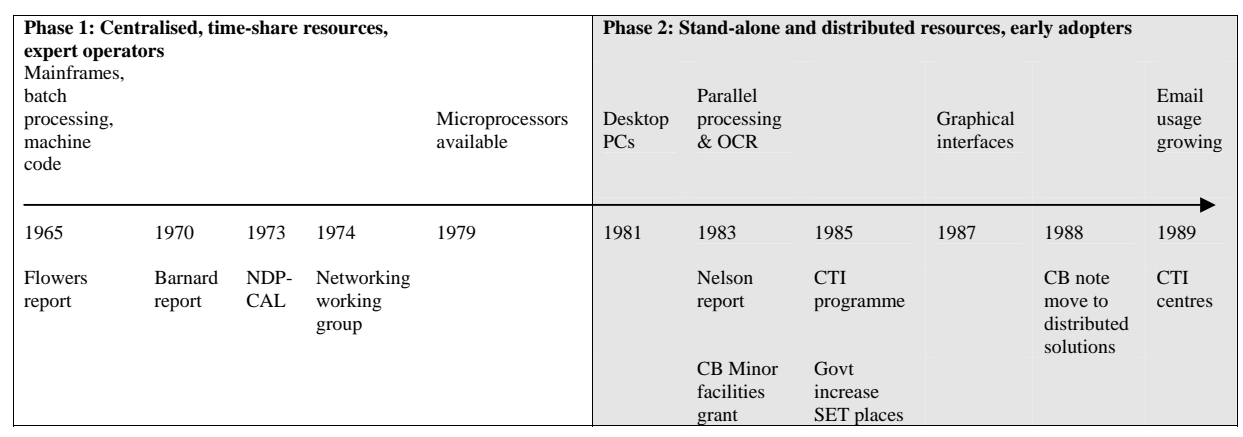

\begin{tabular}{|c|c|c|c|c|c|c|c|c|c|c|c|}
\hline \multicolumn{8}{|c|}{ Phase 3: Networking technologies, collaborative development } & \multirow{2}{*}{\multicolumn{4}{|c|}{ 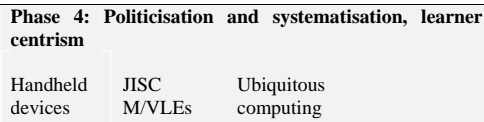 }} \\
\hline JANET & $\begin{array}{l}\text { Internet } \\
\text { launched }\end{array}$ & & $\begin{array}{l}\text { Mosaic } \\
\text { launched }\end{array}$ & $\begin{array}{l}\text { JISC data } \\
\text { services }\end{array}$ & VLEs & & & & & & \\
\hline \multirow[t]{3}{*}{1990} & 1991 & 1992 & 1993 & 1994 & 1997 & 1998 & 1999 & 2000 & 2001 & 2004 & 2005 \\
\hline & $\begin{array}{l}\mathrm{CB} \\
\text { becomes } \\
\text { ISC }\end{array}$ & TLTP & $\begin{array}{l}\text { ISC } \\
\text { becomes } \\
\text { JISC }\end{array}$ & & $\begin{array}{l}\text { Dearing } \\
\text { report }\end{array}$ & $\begin{array}{l}\text { Booth } \\
\text { report }\end{array}$ & $\begin{array}{l}\text { L\&T } \\
\text { strategies }\end{array}$ & LTSN & $\begin{array}{l}\text { UKeU } \\
\text { launched }\end{array}$ & $\begin{array}{l}\text { UKeU } \\
\text { disbanded }\end{array}$ & $\begin{array}{l}\text { DfES/HEFCE } \\
\text { elearning } \\
\text { strategies }\end{array}$ \\
\hline & & & ALT & & & TLTP3 & & & & CETLs & \\
\hline
\end{tabular}

Figure 1. Timeline of technology and policy development in UK higher education

- Technology deployment - a multiplicity of funding initiatives aimed to increase the computer:student ratio in schools, colleges and higher education.

- Software development - programmes were initiated to support the development of subject-specific software tools that have latterly come to focus on generic, collaborative and communicative aspects.

- Communications and networking technologies - as our understanding of education as a social process has evolved, the will to adopt/adapt the potential of such technologies has gathered momentum.

- Staff development - an area that is currently the focus of much activity, but attention to this issue has lagged behind funding for the technologies themselves.

A sixth theme is becoming evident: the need for more learner-centred tools and resources (Joint Information Systems Committee [JISC], 2004a). This issue lags even further behind the belated recognition of staff development needs. The timeline presented in Figure 1 summarises policy development and funding initiatives, characterising the nature of the use of computers in higher education into four phases. Arguably, the most concentrated activity has come within the third and fourth phases-networking technologies and politicisation-and these issues are dealt with in more detail in the exploration of key themes in the next section of this paper.

\section{Four phases of policy development}

The first phase of learning technology development can be characterised by the technologies available before the personal computer: huge, centralised mainframe 
machines, staffed by expert operators, to which access was restricted to those with a specialised skill set. The CBURC was active in this time as a centralised planning authority that was responsible for planning and purchasing the computing capacity that constituted the three regional computing centres (Edinburgh, London and Manchester) that still exist today. Applications to mainstream (i.e. non-technological) education were limited to scientific or at least numerate disciplines until the National Development Programme for Computer Assisted Learning (NDPCAL) programme (1973-1977) was conceived to spread the benefits of computer-assisted learning (CAL) to other disciplines.

Building on the curriculum developments within NDPCAL, the second phase relied on the early adopters (Rogers, 1995) who emerged with the advent of the personal computer (PC). Coupled with the introduction of the minor facilities grant, it became possible for CAL decisions to be devolved to the level of individuals or departments. Staff learned to program and deployed their efforts with students and colleagues. While facilities remained scarce, the 'distributed resource' approach could only be exploited by similarly like-minded colleagues, with the expertise to take and tailor existing stand-alone packages to fit their context. This was a time-consuming and expensive exercise (Teaching and Learning Through Technology [TLTP] phases 1 and 2, 1992). This approach, however, fitted the ethos of higher education at the time, which remains evident today: that of individual academics engaged in the crafting of their disciplinary teaching.

The Internet and graphical browsers that arrived in the early 1990s are the key feature of the third phase of policy development, as they lowered the technical entry barrier at the same time as networking technologies became available to the higher education community. Datasets and services were planned and realised across the academic network, and funding initiatives (TLTP phase 3 ) encouraged interinstitutional collaboration. As this phase progressed, the necessity of collaboration became clear after reviews of poor take-up of previously developed resources (Coopers \& Lybrand/Tavistock Institute, 1996) were published. The Internet also gave rise to benefits of the communicative aspects of learning impossible with earlier technological developments.

The fourth, and current, phase stems from the initial excitement of the Internet as a tool to make a difference in the use of technology-supported learning in higher education. With this technological development came the realisation that the very lack of control that characterises this technology (Naughton, 2001) appeals to the craft-orientated academics mentioned earlier. As growing numbers of individuals exploited the new technologies, the skills acquired in the sector, along with previous significant funding initiatives, grew in importance and the focus of learning technologies turned to scaling up the early adopters' (Rogers, 1995) efforts, with the enhanced support of national funding programmes from bodies such as the JISC (see for example JISC, 2004b). These issues are explored further in the six key themes now detailed that shaped the direction and development of learning technology policy, research and practice today, as summarised in Table 1 . 
Table 1. The relationship between technological developments and policy focus

\begin{tabular}{ll}
\hline Four phases of development & Six themes derived from the policy review \\
\hline $\begin{array}{l}\text { Centralised, time-share resources and expert } \\
\text { operators }\end{array}$ & Technology development \\
$\begin{array}{l}\text { Stand-aloneanddistributedresources,earlyadopters } \\
\text { Technology deployment }\end{array}$ & Software development \\
$\begin{array}{l}\text { Networking technologies and collaborative } \\
\text { development }\end{array}$ & Communicative tools \\
$\begin{array}{l}\text { Politicisation, systematisation and a concern for } \\
\text { learner-centrism }\end{array}$ & Staff development \\
& Content development \\
\hline
\end{tabular}

\section{Technology development}

The Government's acceptance of the Flowers report of 1965 decreed the use of computers in higher education as a specialism worthy of a dedicated committee. The CBURC was set up to judge the merit of funding requests and, importantly, had a responsibility for forward projection of requirements. The early reports demonstrate a concentration of effort in providing adequate (and, latterly, compatible) hardware and operating systems. There was little forward vision, with each successive report detailing replacements for machines provided in the previous funding cycle. This is unsurprising given the scale of technological change, from the hugely expensive room-sized mainframe of 1965 to the desktop PC of 1981. By way of critique of the CBURC, this lack of foresight is particularly evident around the time of microprocessor development and deployment in the early 1980s, which proved to be a technological revolution with the power to defy central planning.

A clear secondary goal of the CBURC's policies was support for the fledgling British computer industry. This led to positive promotion of science and technology, with more places becoming available in higher education, moving computing from a specialist postgraduate discipline (Barnard, 1970) to the third most popular first degree subject in 1999/2000 (Higher Education Statistics Agency (HESA), 2001). Sheer numbers mask a wide diversity of course offerings, however, with most students studying the application of information technology to other areas rather than computer science.

Cheap, powerful computers became widely available in UK higher education (see below) and they were equipped with the capabilities prioritised by the CBURC: graphical displays, interactivity, connectivity and personal storage space. Other developments predicted in the late 1970s, flat displays, speech synthesis, tactile information (McKenzie et al., 1978), are only now being widely adopted. With these goals realised, some areas of computer science research now pursue immersive virtual reality environments, leading to an escalation in costs for cutting-edge facilities that is no longer overseen by a coordinating body. Just as importantly, however, 
the applicability of information and communication technologies (ICTs) to other disciplines is now regarded as vitally important in the development of UK higher education to meet the globalisation challenge (Department for Education and Skills [DfES], 2003) and large sums of money continue to be invested to encourage ICTbased routes through education.

If the CBURC was remiss in not recognising the potential of the microprocessor, it was far-sighted in overseeing development of a UK-wide academic network based on open source standards. The joint network team (later reformulated by the JISC as UKERNA) (Arbuthnott, 1994) and the regional consortia developed to provide the networking services are still the backbone of UK academic computing networks today. Naughton (2001) reports a 1998 comment by a disciple of Bob Taylor (onetime chief of both Advanced Research Projects Agency (ARPA) and Palo Alto Research Centre (PARC), American organisations at the heart of Internet development): 'if the internet hadn't existed, we couldn't invent it now' (Naughton, 2001, p. 275), citing the 'tyranny of the bottom line'. Without the CBURC to steer a cooperative, collaborative approach to networking development, the fragmentation that dominates learning technology research through its multiplicity of funders could give rise to competing standards and incompatibility. Similar initiatives to systematise learning with rather than about computers are now much in evidence (DfES, 2003; HEFCE, 2003 e-learning strategy consultations).

It is clear that the attempts by the CBURC and Nelson (1983) to specify hardware, operating systems and software requirements were not particularly helpful in a time of rapid technological development. However, the adherence to a consultative, cooperative approach, especially for networking technologies, has had clear benefits for the deployment of ICTs in higher education today, where interoperability concerns across the network are not an issue. However, proprietorial systems for records and learner management (i.e. those systems focused not on delivery, but on local operation) now give rise to many issues precluding joined-up service delivery.

\section{Technology deployment}

In the early years of computer deployment in UK higher education, there was a concerted effort to provide computing power to universities on a regional, time-share basis to further research in physical sciences to which such tools could add value. It was also recognised, however, that there were other disciplines that could also benefit from the provision of such resources (Flowers Committee, 1965), and that the divide between research and teaching uses was unhelpful (Barnard, 1970). The initial deployment of available technologies was concentrated in particular regions, with requests for funds approved on the basis of collaborative access to scarce and expensive resources. Three regional centres were mooted, with the aim of complementarity in service provision.

For as long as computing resources remained scarce through cost and operational complexity, the CBURC was in a strong position to dictate overall policy. However, increasing computing power and diminishing costs, and a need to consider 
computers for teaching as well as research purposes, undermined the authority of a single decision-making body. The introduction in 1983 of the minor facilities grant allowed individual institutions more control over spending, and the advent of the PC, as noted earlier, facilitated local deployment and control of computing resources. Nelson (1983) noted the different approaches of universities and the then polytechnics, particularly with respect to the provision of central computing support services.

Decentralised responsibility (between the CBURC, the University Grants Committee and the research councils) led to divided responsibilities, which ultimately led to the demise of the CBURC. The need for computers for university administration, outside the remit of the CBURC and the research councils, and the advent of the PC in 1981, placed new funding mechanisms on the agenda. Technological change continued to be rapid and the increasing speed, power and capability were set against rapidly diminishing costs. Computers are now provided through a range of funding provision, eliminating the previous delineation in use that was dependent on the equipment's source of funding. This has allowed higher education institutions to acquire many more PCs and use this strategy as a marketing tool to attract students. This wide availability, and the implementation of microprocessor technology in all areas of business and leisure, has led to a growing demand for graduates with technical knowledge and computing skills.

Nelson (1983) was the first representative on the CBURC from a polytechnic. Clearly, she came from a culture that had historically focused on teaching rather than research provision, and her report was particularly far-sighted in the potential uses of technology. She noted increasing pressure from industry, school and home/ leisure users, leading to an expectation of computer skills becoming part of the tertiary education curriculum. In terms of deployment, the report proposed a minimum workstation specification for teaching purposes, and advocated an across the disciplines average of 1:5 computer:student ratio by 1990 . This recognition of multiple disciplinary uses of computers built on the CBURC target of 20 terminals per 1000 students set in 1976. The growing pervasiveness of ICT in higher education is further illustrated by the Dearing recommendation that by 2000/2001, 'all students [would] have open access to a networked desktop computer' (NCIHE, 1997, recommendation 46).

An implication of the Dearing recommendation, however, was the emergence of what Holderness (1998) called the 'information poor'. Universal provision was clearly outside the scope of higher education budgets, displacing costs onto students along with the idea that the possession of a PC was a pre-requisite to succeed in higher education. However, by the mid-1980s, hardware provision and diminishing costs allowed universities to provide greater facilities than before. Later that decade, as student numbers began to expand without a commensurate rise in staff numbers, some academics turned to CAL packages as a way to provide content to a growing audience. The Computers in Teaching Initiative (CTI) and, a little later, the TLTP funded explorations of software provision, which was now recognised as a barrier to the wider adoption of ICTs. 


\section{Software development}

In 1975, the CBURC set up a software provision subcommittee. Both the Barnard (1970) report and the CBURC (1972) made note of the Wilkes proposal to develop a computer programming teaching aid complete with diagnostic tools for self-study among undergraduates. Despite funding being approved, there was no implementation or evaluation report of this tool, questioning the legitimacy of centralised software development approaches. This was driven by the conflicting needs of proprietary operating systems then in use, but the deployment of DOS-based PCs and industry-standard tools in the early 1980s made compatibility less of an issue. In 1985, the CTI was introduced, focusing on subject-specific software developments to build on the NDPCAL initiative (1973-1977) that had been limited by the tools available. Such focused projects were seen as the way forward for software development and use in higher education. The possibility of developing bespoke software for a particular curriculum area appealed to enthusiasts, although Reigeluth (1993) has identified less-innovative lecturers who are less able to exploit such software and TLTP evaluations (Coopers \& Lybrand/Tavistock Institute, 1996; HEFCE, 1999) have identified minimal uptake of products outside of the originating institutions.

The author of the Information Systems Committee (1992) report 'Beyond Lectures' suggested that entry-level core curricula could be identified in various disciplines, and that common software could be exploited in this area. A reductionist philosophy to software development identifies economies of scale through widespread adoption of centrally developed CAL packages that will defeat the 'not invented here' syndrome. In this respect, the popularity of generic virtual learning environments supports this position, and the Open University has extended the concept with reusable software shells filled with disparate content. However, recent reports (SoURCE, 2001) and previous evaluations (HEFCE, 1999) have shown that individuation remains important and that non-customisable resources are rarely adopted outside originating institutions (Sharpe, 2004).

The CBURC (1972) advocated developing models of software development, but costs put this outside higher education reach. Industry developed methodologies such as Computer Aided Software Engineering (CASE) and Structured System Design (SSD) for software design and engineering in business-driven contexts, but education remains outside adoption of these techniques to this day, preferring 'craft' (i.e. individual) approaches to each successive development. Nelson (1983) identified 14 potential uses for information technology in education, including assessment, communications and learner management. To date, however, the only widespread adoption of a dominant application directly related to the students' learning experiences is that of institutional virtual learning environments, with individual institutions arriving at their own decisions after evaluation by (usually) non-academic practitioners (UCISA, 2001). Other tools, such as email, document sharing and video-conferencing, all have applications in the student learning arena. However, they are mostly used to shape new forms of collaborative academic work, in terms of communication or research, rather than widely adopted as ways of interacting with students. 
The CTI functioned from 1985 until 1999 with its discipline-specific focus. Software produced through TLTP phases 1 and 2 was often recognised as being of high quality (HEFCE, 1999) and well promoted through the CTI (HEFCE, 1998). Even with greater standardisation of computer architecture and operating systems, transferability remained problematic. Developments in the early 1990s made more generic usage of ICT in higher education a possibility. The advent of Mosaic, the first graphical browser, in 1993 opened up Internet usage to non-technical academic users. TLTP phase 3 was instigated to address the problems of integration and embedding (HEFCE, 1997) and has been the first initiative able to exploit the potential of the Internet. The CTI was disbanded in 1999, to be replaced by the Learning and Teaching Support Network (LTSN) generic and subject centres, which were in turn subsumed into the overarching Higher Education Academy in 2004, thus building e-learning into a bigger and more wide ranging learning and teaching development system.

Exploitation of the Internet by systemically funded initiatives has taken the form of project outcome dissemination. Adaptation of materials for web delivery has taken place, but these materials are often password protected, again denying transferability, except within project consortia. Where adaptation of materials remains problematic (Sharpe, 2004), more interest has been generated in the communicative and discursive aspects of the web (Holley, 2001) rather than simple delivery of content via that medium. The JISC/NSF (2001) call for proposals made it clear that there appeared to be little to gain from projects that focused on developing new materials, and that efforts should focus on the use of existing electronic content and generic delivery tools to further learning. Following Dearing's support of resource-based learning and information skills as critical to future graduates' success, the issue of academic development became key. The Booth (1998) report set an expectation of ICT use for lecturers in higher education as another 'tool of the trade', and the availability of a user-friendly Internet interface (Berners-Lee and Andreesen, in Naughton, 2001) began the expansion of communicative ICT usage to academic staff of all disciplines.

\section{Communications and networking technologies}

Government priorities and money were, for a long time, swayed towards tangible ends. Numbers of computers accessible to staff and students have been a measure of success in ICT usage. The changing nature of ICTs, specifically networking technologies, means success is now measured in connectedness and bandwidth. The decision to adopt open source technologies for the academic computing network and the provision of funds for institutional Local Area Network development were important decisions from the CBURC. The existence of this infrastructure has been an important driver towards web-based delivery. If reuse of CAL materials in new contexts has proved difficult, the web has been adopted in higher education at an incredible rate. For example, Kahn (1996) documented the development of SuperJANET (56 users in 1993, 120 users in 1994) and the London metropolitan area network that served over 40 institutions. 
The importance of this medium in UK higher education cannot be underestimated: it is now a requirement of virtually all research funding that successful projects will maintain comprehensive websites as an important form of dissemination. Naughton (2001) is transfixed by the potential of the Internet, and the proceedings of learning technology conferences contain many contributions detailing the use of managed learning environments (MLEs) or virtual learning environments (VLEs), regardless of the academic subject or topic under consideration. Web-based development and delivery are often key goals for higher education institutions, featuring in the learning and teaching strategies required by the funding council. This is despite Stoll's (2000) objections. He reports with dismay the libraries converted to learning resource centres where serendipitous browsing among books is an objective that now takes second place to individual work within an online environment, but containing rows of computers barely used.

The limited implementation of subject-specific CAL, from NDPCAL in the 1970s to TLTP in the 1990s, has concerned funders and academics for some time. Many blame this non-implementation on the 'not invented here' syndrome or lack of staff skills (see next section), but this may be an overly simplistic explanation. There is now a cadre of experienced and committed staff who still find adaptation to new contexts difficult. Web-based materials, however, are more easily accessible, fairly easily customisable and mostly free at point of access. This has opened up world-wide communication and collaboration opportunities and broadened the understanding of education as a social rather than mechanistic process, as noted by commentators from Vygotsky (1978) onwards.

What is important is that there has long been a focus on measurable deliverables. Numbers of computers, or software development, are highly visible measures funded through government policy. What is not as visible or as measurable is people's ability to access and use effectively the computers or software provided under the initiatives detailed in this section.

\section{Staff development}

A major problem with the increased usage of computing facilities was the lack of staff expertise and support. The CBURC, recognising the lack of staff skills and the associated rise in support costs as a problem, noted the:

increasing number of users who are inexperienced in computing techniques and need extensive advisory services. We are taking steps to curtail recurrent costs; directors of university computing centres are being encouraged to purchase hardware aimed at reducing the number of staff required to provide the computing service. (CBURC, 1976, pp. 13-14)

Both the CBURC and Nelson reports propose staff training to counteract the problem. The CBURC policy statement (1976, p. 12), in support of a national computing network, noted that 'reliable communication links can be established', whereas Heeks's (1987) study found only $15 \%$ usage for email in academic departments. This 
slow staff uptake of services that had clearly been available for some time may be due to the predominance of investment in hardware and software at the expense of staff awareness and training. The position had not changed much a decade later when the Dearing report drew attention to the sound infrastructure developed through earlier capital investment, but noted that 'the use of new technologies for learning and teaching is still at a developmental stage' (NCIHE, 1997, para. 68).

It could be argued that as understanding of the use of computers in education has evolved, a wide-ranging understanding of tools and products has become more important. The re-skilling and awareness raising of higher education staff is therefore the chief challenge for successful adoption. At the start of this decade, it became noticeable that calls for funding proposals (JISC/NSF, 2001; ESRC, 2002) limited funding for equipment and infrastructure, and contained clear strands investigating staff skills and reward issues. There is much concern in higher education that students now enter higher education with greater information technology abilities than their lecturers (Stephens \& Creaser, 2002) and that an inherent 'fear factor' among staff may preclude wider adoption of ICT. Until sufficient reward is provided to see ICT usage as another 'tool of the trade' (Booth, 1998), this situation is unlikely to change.

For those who have developed significant skill sets through the various initiatives noted earlier, two problems arise-and current funding focuses on these (JISC, 2004b). First, content adaptation remains difficult to accomplish and disseminate. Littlejohn (2003) explores the potential of reusable learning objects to address this issue. While repositories have been developed, for experienced staff the issue may be that finding and tailoring reusable learning objects is just as time-consuming as developing their own artefacts. This is often dismissively labelled as 'reinventing the wheel', without any consideration of the benefits to academics of developing their own materials in this way.

Second, the move to institutional tools, most commonly VLEs, removes much of the individual creativity that led to resources tailored to specific student learning needs or difficulties (Cox et al., 1974; Stuart et al., 2004). The pedagogical constraints of the VLE are now recognised, and recent funding initiatives (JISC, 2004a, 2004b) have tended towards encouraging experienced staff to develop opensource tools to allow greater interoperability or more personalised tools and environments. This shift in policy may support more creative developments closely targeted to learner needs reminiscent of the early adopters of the 1970 s, rather than the critical mass arguments given for institutional VLEs or the UKeU.

\section{Politicisation and learner-centrism}

I want today to make a significant statement about the future direction of higher education ... Learning has become big business ... New providers are already expanding into the learning environment to meet this demand, particularly in the USA ... We must have big aspirations, even if we are a small country ... The impact of new technologies on learning are now well rehearsed ... Nonetheless, it is clear that virtual learning is an industry which is striding forward all around us ... But the challenge is also a national one-how can we best, as a country, respond to the wave of change that e-learning is 
bringing to higher education throughout the globe?... That is why I can announce that HEFCE will bring forward proposals for a new collaborative venture between universities and private sector partners, under the working title of the 'e-Universities' ... It will be clearly positioned overseas as the flag-carrier for the best of $\mathrm{UK}$ higher education in web-based delivery. (Blunkett, 2000)

These extracts from Blunkett's (2000) Greenwich speech highlight a fundamental shift away from individual innovation to a systematic and politically-driven model of online education, reflecting wider developments in UK higher education (Barnett, 2000). Large-scale commercial products, such as VLEs, fit this model well and, while their use began in the late 1990s, the uptake of this kind of tool, reminiscent of the first phase of learning technologies (centralised, expert operators), gathered pace with the sustained proprietary tool roll-out into the early part of this century (UCISA, 2001). This approach was supported by the area's significant funding body (see, for instance the JISC MLE/VLE programme) and, having learned the lessons of earlier eras, was coupled with funding for staff development via the teaching quality enhancement fund. Staffing grew and priorities reflected the new technologically enhanced environment (Gosling, 2001). In 2004, the HEFCE released a call for proposals for centres of excellence in teaching and learning. Many of the bids to this call suggested a variety of e-learning support, as institutions were keen to maximise their investment in commercial VLEs (HEFCE, 2004). At the same time, the JISC (2004a) were keen to encourage the development of open-source tools, to maximise the interoperability of proprietary systems.

Between 2001 and 2004, the government-sponsored UkeU, together with a commercial partner, spent a significant sum of money on developing a single elearning platform to rival the other commercial systems that were most popular in universities. This aligned with the development of the LTSN, creating two 'big systems' as the focus for learning technology development. At the same time, research continued to follow a 'case study' approach, reporting on individuals' niche implementations of technology. These have been criticised for their lack of robustness, particularly in relation to wider applicability or longitudinal studies (Mason, 2002), a situation that the LTSN has been trying to address through both generic and subjectspecific e-learning projects. While one big system (UKeU), has collapsed, the other (LTSN) has grown bigger through its amalgamation with the Institute for Learning and Teaching.

For those who work in the complex world of learning technologies, Blunkett's (2000) speech has some daunting overtones-'big business', 'big aspirations', 'wellrehearsed'-in relation to the national and global benefits of e-learning. While the $\mathrm{UKeU}$ met a sorry end in the middle of 2004, and may be accused of a naivety of purpose (Goddard, 2005), increasing systematisation is still evident in the funding regime of the area (JISC, 2004a; but see below). Sector investments in proprietary tools (common to the first phase of policy in this area) has necessitated secondary investment to allow them to inter-operate, a focus of the third phase as a common technology (the Internet) characterised increasing and pluralistic activity. 
Politicisation and systematisation of e-learning appears endemic, as policy and funding pursues large-scale development to harness potential in this area. This began with Blunkett's (2000) pronouncement on the UKeU but does not seem to have ended with the ill-fated institution's demise. The recently announced centres of excellence in teaching and learning (HEFCE, 2005) and the DfES/HEFCE elearning strategies are manifestations of this systematisation, while other funding initiatives focus on the need for more personalised learning experiences (JISC, 2004a). Research in the area is now foregrounding the need for more learner-centric developments (Thorpe, 2002), thereby highlighting a disjuncture between policy and practice. The promise of learner-centrism has not yet been realised by the available commercial tools and there appears to be support for a return to the second phase of learning technology policy, where individuals innovate in a learner-centred way.

\section{Conclusions}

The first phase of policy in online learning shares an important feature with the current situation: that of gatekeepers. In the period from 1965 to 1980, tools and resources were scarce and specialised, and experts were needed to operate them. As hardware has become plentiful and software easier to use, however, activity has tended to group into specialised units and become the subject of institutional strategies. Arguably, the narrow focus of the early days (proprietary systems, programs that were not easily customisable) is being repeated through institutional roll-out of VLEs. But a tension in 'big systems', as represented by the UKeU, may now be discernible as smaller projects focusing on learner need (JISC, 2004a) are funded. Overarching policy directions such as the soon to be released HEFCE e-learning strategy, however, may yet lead to institutional policies that preclude a return to the individual innovators who characterised the second and third phases of policy development.

In specialised corners of the curriculum, CAL use remains. However, the advent of generic tools such as communication channels, the Internet and presentation software has gained far more credibility in terms of participation for both staff and students. Reliable technologies and tools with lower entry barriers may be more readily acceptable to staff who lack sufficient skills and knowledge to pursue more complex ICT adoption. For experienced practitioners, however, the recent focus on reusable learning objects continues to be a concern. Finding and customising such resources is still so time-consuming that skilled individuals may prefer to 'reinvent the wheel' by designing and developing their own resources. Continuing reluctance to adopt new technologies can be attributed not only to concern over proprietary tools, but more importantly to a generally limited pedagogical understanding among higher education staff and lack of incentive towards development in this area.

While mainstream standards have converged in terms of processor power and networking protocols, the lack of an overarching strategic planning body can be seen in differing adoption patterns for MLEs/VLEs. Institutions make their own MLE/ VLE choice, be that commercial or bespoke. Already, migration from one system to another is problematic (Morris, 2004). The sums invested in licensing for commercial 
products that accompany significant efforts in in-house training make it increasingly difficult for those who have adopted an institutional policy to remain flexible if new and potentially more powerful tools come to market, while another outlet for technological creativity is sustained as open-source software gains a hold. By 2004, significant sums were being invested in additional tools to extend the functionality of commercial or open-source products, and a great deal of effort expended in creating new interfaces to allow interoperability among proprietary products (JISC, 2004b).

This review covers 40 years of policy for computer use in UK higher education and highlights the significant shifts in the types of technology available for deployment in higher education. An early focus was to provide adequate and compatible regionally distributed resources for research purposes. The need to provide for teaching followed soon after, and a central body (the CBURC) was charged with projecting future needs. By the mid-1980s, the focus was shifting from teaching computing skills to using technology to support learning in a diverse range of disciplines. By the early 1990s, the application of computing to administrative and library needs was recognised, and existing funding arrangements were deemed inadequate. This coincided with an overhaul of funding in UK higher education generally. The creativity of the early adopters, who matched tools and resources closely to student learning need (Cox et al., 1974), has been overlooked in more recent strategically intentioned developments, but current funding may be beginning to redress this balance. Lessons learned from the demise of the UKeU may signal the end of 'big systems' and a return to individual innovation, rather than further sustaining Blunkett's (2000) rhetoric of e-learning as economic necessity—or 'putting money before thinking' (Elton, 2005) - that has characterised the area since the 1997 Dearing report.

\section{Acknowledgements}

The author is grateful to Michael Flanagan and Lewis Elton for helpful comments on an earlier draft of this paper, and to Sam Brenton for his thoughts and for locating the infamous IBM quote at the start of this article.

\section{References}

Arbuthnott, J. (1994) FISC introductory report R4/94. Available online at: www.jisc.ac.uk/pub/ r4_94.html (accessed 18 January 2005).

Barnard, A. G. (1970) Teaching computing in universities: report of the joint working party (London,University Grants Committee/CBURC).

Barnett, R. (1994) The limits of competence: knowledge, higher education and society (Buckingham, SRHE/Open University Press).

Barnett, R. (2000) Realising the university in an age of supercomplexity, Buckingham: SRHE/ Open University Press

Blunkett, D. (2000) Secretary of State for Education speech given at the University of Greenwich, 15 February. Available online at: http://cms1.gre.ac.uk/dfee/\#speech (accessed 18 January 2005). 
Booth, C. (1998) Accreditation and teaching in higher education: consultation paper (London, CVCP).

Computer Board for Universities and Research Councils (1968-1991) Reports of the Computer Board for Universities and Research Councils (London, HMSO).

Conole, G. (2002) The evolving landscape of learning technology, ALT-f, 10(3), 4-18.

Coopers \& Lybrand/Tavistock Institute (1996) Evaluation of the teaching and learning technology programmes (Bristol, HEFCE).

Cox, M., Elton, L. \& Gray, R. (1974) Use of computer methods in an introductory quantum mechanics course, International fournal of Mathematics, Education, Science and Technology, 5, 157-160.

Department for Education and Skills (2003) A unified strategy for e-learning (London, DfES). Available online at: www.dfes.gov.uk/elearningstrategy (accessed 18 January 2005).

Elton, L. (2005) Personal communication (London, UCL).

ESRC (2002) Teaching and learning research programme, call for proposals. Available online at: www.esrc.ac.uk (accessed 18 January 2005).

Flowers Committee (1965) Computers for research. Report of a working party for the Universities Grants Committee, UGC 7/635 (London, HMSO).

Goddard, A. (2005, January 14) Fender takes rap for UKeU, Times Higher Education Supplement, p. 9.

Gosling, D. (2001) Educational development units in the UK: what are they doing five years on?, International fournal for Academic Development, 6(1), 74-90.

Hawkridge, D. (1999) Thirty years on, BJET! and educational technology comes of age, British Fournal of Educational Technology, 30(4), 293-304.

Heeks, R. (1987) Computerisation in academic departments: a survey of current practice. British Library R\&D report 5939 (London, British Library).

HEFCE (1997) Teaching and learning technology programme phase 3: invitation to bid. (Bristol, HEFCE).

HEFCE Report 98/47 (1998) An evaluation of the computers in teaching initiative and teaching and learning technology support network (Bristol, HEFCE).

HEFCE (1999) The use of TLTP materials in UK higher education (Bristol, HEFCE).

HEFCE (2003) Consultation on HEFCE e-learning strategy. Available online at: www.hefce.ac.uk/ pubs/circlets/2003/c121_03.htm (accessed 18 January 2005).

HEFCE (2004) Centres for excellence in teaching and learning: bids proceeding to stage 2. Available online at: http://www.hefce.ac.uk/learning/TInits/cetl/s2bids.asp (accessed 18 January 2005).

HEFCE (2005) Centres for excellence in teaching and learning - list of successful bids. Available online at: http://www.hefce.ac.uk/learning/tinits/cetl/final/ (accessed 7 March 2005).

HESA. (2001) HE students by subject of study 1999/2000. Available online at: www.hesa.ac.uk (accessed 18 January 2005).

Holderness, M. (1998) Who are the world's information poor?, in: B. Loader (Ed.) Cyberspace divide: agency, equality and autonomy in the information society (London, Routledge).

Holley, D. (2001) Which room is the virtual seminar in, please? Paper presented at the LTSN Business and Management Conference, Kendal

House of Commons Education and Skills Committee (2005) UK e-University Third Report of Session 2004-05 (London, The Stationery Office).

Information Systems Committee (1992) Beyond lectures: the report of the Information Systems Committee Courseware Development Working Party (CTISS).

Joint Information Systems Committee (2004a) e-learning tools projects. Available online at: http:// www.jisc.ac.uk/elearning_tools_home.html (accessed 18 January 2005).

Joint Information Systems Committee (2004b) Framework programme. Available online at: http:/ /www.jisc.ac.uk/index.cfm?name=programme_frameworks (accessed 18 January 2005). 
Joint Information Systems Committee/NSF (2001) Digital classrooms call for proposals. Available online at: www.jisc.ac.uk (accessed 18 January 2005).

Kahn, M. (1996) The development of the London MAN. Available online at: www.lonman.net.uk/ describe.htm (accessed 18 January 2005).

Littlejohn, A. (Ed.) (2003) Reusing online resources: a sustainable approach to e-learning (London, Kogan Page).

Mason, R. (2002) Presentation to ALT Policy Board, Aston University, 3 July.

McKenzie, J., Elton, L. \& Lewis, R. (1978) Interactive computer graphics in science teaching (Chichester, Ellis Horwood).

McNay, I. (Ed.) (2000) Higher education and its communities (Buckingham, SRHE/Open University Press).

Morris, H. (2004) A tale of two universities: evaluating the effects of different approaches to the introduction of virtual learning technologies. Paper presented at Shock of the Old 4, Oxford, April.

Naughton, J. (2001) A brief history of the future: the origins of the internet (London, Phoenix).

NCIHE (1997) The Dearing Report. National Committee of Inquiry into Higher Education (London, HMSO).

Nelson, D. A. (1983) Report of a working party on computer facilities for teaching in universities (London, CBURC).

Ravenscroft, A. (2003) From conditioning to learning communities: implications of fifty years of research in e-learning interaction design, ALT-f, 11(3), 4-18.

Reigeluth, C.M. (Ed.) (1993) Instructional design theories (NJ, Lawrence Erlbaum Associates).

Rogers, E. (1995) The diffusion of innovations (4th edn) (New York, Free Press).

Sharpe, R. (2004) Initial positioning report for e-learning and pedagogy research study: effective resources and interventions for e-learning (Bristol, JISC).

Smith, J. (2004) Learning technology: early policy review. Available online at: http:// www.ee.ucl.ac.uk/ jsmith/epr.htm (accessed 7 March 2005).

SoURCE (2001) Final report. Available online at: http://cortez.open.ac.uk/source/ lessons_learned.htm (accessed 18 January 2005).

Stephens, D. \& Creaser, C. (2002) Information science student IT experience and attitude toward computers: results of a five year longitudinal study, Italics, 1(2). Available online at: http://www.ics.ltsn.ac.uk/pub/italics/issue2/dstephens_b/005.html (accessed 18 January 2005).

Stoll, C. (2000) High-tech heretic: reflections of a computer contrarian (New York, Anchor).

Stuart, S. A. J., Brown, M. I. \& Draper, S. W. (2004) Using an electronic voting system in logic lectures: one practitioner's application, Fournal of Computer Assisted Learning, 20(2), 95-102.

Thorpe, M. (2002) From independent learning to collaborative learning: new communities of practice in open, distance and distributed learning, in: M. R. Lea \& K. Nicoll (Eds) Distributed learning: social and cultural approaches to practice (London, RoutledgeFalmer).

UCISA (2001) Management and implementation of virtual learning environments: a UCISA funded survey. Available online at: www.ucisa.ac.uk (accessed 18 January 2005).

Vygotsky, L.S. (1978) Mind in society: the development of the higher psychological processes (Cambridge, MA, The Harvard Press) (Original work published 1930 [New York, Oxford University Press]).

Watson, T. (1943) Chairman of IBM, Macleans magazine, April 1998, p. 60. 